Check for updates

Cite this: RSC Adv., 2018, 8, 38733

Received 9th August 2018

Accepted 11th November 2018

DOI: $10.1039 / \mathrm{c} 8 \mathrm{ra06709k}$

rsc.li/rsc-advances

\section{Characterization of reactive intermediates formation in dacomitinib metabolism and bioactivation pathways elucidation by LC-MS/MS: in vitro phase I metabolic investigation}

\begin{abstract}
Mohamed W. Attwa, (D)* Adnan A. Kadi and Ali S. Abdelhameed
Dacomitinib (DCB) is a second generation irreversible tyrosine kinase inhibitor (TKI) that is claimed to overcome the disadvantages of the resistance developed by the first line epidermal growth factor receptor (EGFR) TKIs. In the current study, metabolites of phase I for DCB were systematically explored. DCB reactive metabolites were also investigated in rat liver microsomes in presence of potassium cyanide or methoxylamine that were employed as capturing agents for iminium reactive intermediates and aldehyde, respectively, to form stable complexes which can be detected by LC-MS/MS. As a result, four in vitro phase I metabolites were observed with major pathway of piperidine ring hydroxylation. Additionally, two potentially reactive intermediates, one aldehyde and one iminium ions were characterized. Two different pathways of bioactivation were ultimately proposed.
\end{abstract}

\section{Introduction}

Lung carcinoma is the principal cause of death among all cancer types. Non-small cell lung cancer (NSCLC) represents the most widespread (around 90\%) of all lung cancer in patients. ${ }^{1-5}$ During the past few years, the epidermal growth factor receptor (EGFR) signaling pathway as a therapeutic target in NSCLC has gained more recognition. ${ }^{6}$ Inhibitors of the tyrosine kinase (TKIs) that affect the epidermal growth factor receptor (EGFR) are very effective against most EGFR mutations with a good therapeutic window. First line EGFR TKIs (e.g. erlotinib and gefitinib) had a very good response against these active mutations at the beginning. ${ }^{7,8}$ Unfortunately, acquired resistance (around 60\%) and toxicities that occurred in treatment ${ }^{9,10}$ reduce their therapeutic efficacies..$^{11,12}$

DCB is a second generation irreversible EGFR TKIs that overcomes the disadvantages of the acquired resistance first line EGFR TKIs. ${ }^{13-15}$ When compared with gefitinib, DCB improved progression-free survival in the management of patients with positive EGFR mutation NSCLC. DCB is regarded as a new way of treatment for this medical case. ${ }^{16}$ The U.S. Food and Drug Administration (FDA) accepted Pfizer's application for DCB as new drug and granted priority review for the first-line management of patients with locally advanced or metastatic NSCLC with EGFRactivating mutations. On September $27^{\text {th }} 2018$ FDA approved DCB tablets (VIZIMPRO ${ }^{\mathrm{TM}}$ ), for the first-line treatment of

Department of Pharmaceutical Chemistry, College of Pharmacy, King Saud University, P. O. Box 2457 Riyadh, 11451, Saudi Arabia. E-mail: mzeidan@ksu.edu.sa; Fax: +966 114676 220; Tel: +966 114670237 individuals suffering from metastatic NSCLC with EGFR exon 19 deletion or exon 21 L858R substitution mutations. ${ }^{17}$ A marketing authorization application for DCB was also accepted by the EMA (European Medicines Agency) for the same indication ${ }^{\mathbf{1 8}}$

The most common severe (grade 3 ) adverse reactions of DCB were acne (in 14\% of patients) and diarrhea (in $8 \%$ of patients). In spite of its increased adverse reactions particularly in the skin and gastrointestinal tract, the potent activity of DCB allowed for consideration of this effective therapy in EGFRpositive NSCLC. ${ }^{19-21}$ Proteins in the body can be modified by covalent binding to reactive metabolites that is regarded as the primary step in organ toxicities. ${ }^{22,23}$ In most cases, such reactive intermediates are produced through reactions of phase I metabolism. The reactive intermediates in drug metabolism can cause many side effects. As a result of their transient nature, a trapping agent is always used to trap reactive intermediates to facilitate the formation of stable adducts. The formed adducts can be isolated from the incubation mixture, detected and characterized by LC-MS/MS. ${ }^{24,25}$

Chemically the structure of DCB encompasses a piperidine ring and a butenamide group. Drugs contains piperidine ring are subjected to bioactivation that forms iminium ions intermediates which may be stabilized by KCN forming cyano adducts. Butenamide group undergoes bioactivation through oxidative dealkylation developing an unstable reactive aldehyde that can be stabilized by reaction with methoxylamine forming oxime. ${ }^{26-28}$ These stabilized adducts may be extracted, separated and identified using LC-MS/MS. ${ }^{\text {24-26,29,30 }}$

Upon literature review, one article was found that focused primarily on the pharmacokinetics of dacomitinib in human. ${ }^{31}$ 
Table 1 Adjusted parameters of the proposed LC-MS/MS methodology



Such study was aimed at characterizing the principal elimination routes of dacomitinib in humans. The study did not involve complete metabolic profiling with structural elucidation of dacomitinib metabolites. In contrast, the main target of the present work is reactive metabolites screening to provide a possible reason for toxicity of DCB via in vitro metabolic

A)

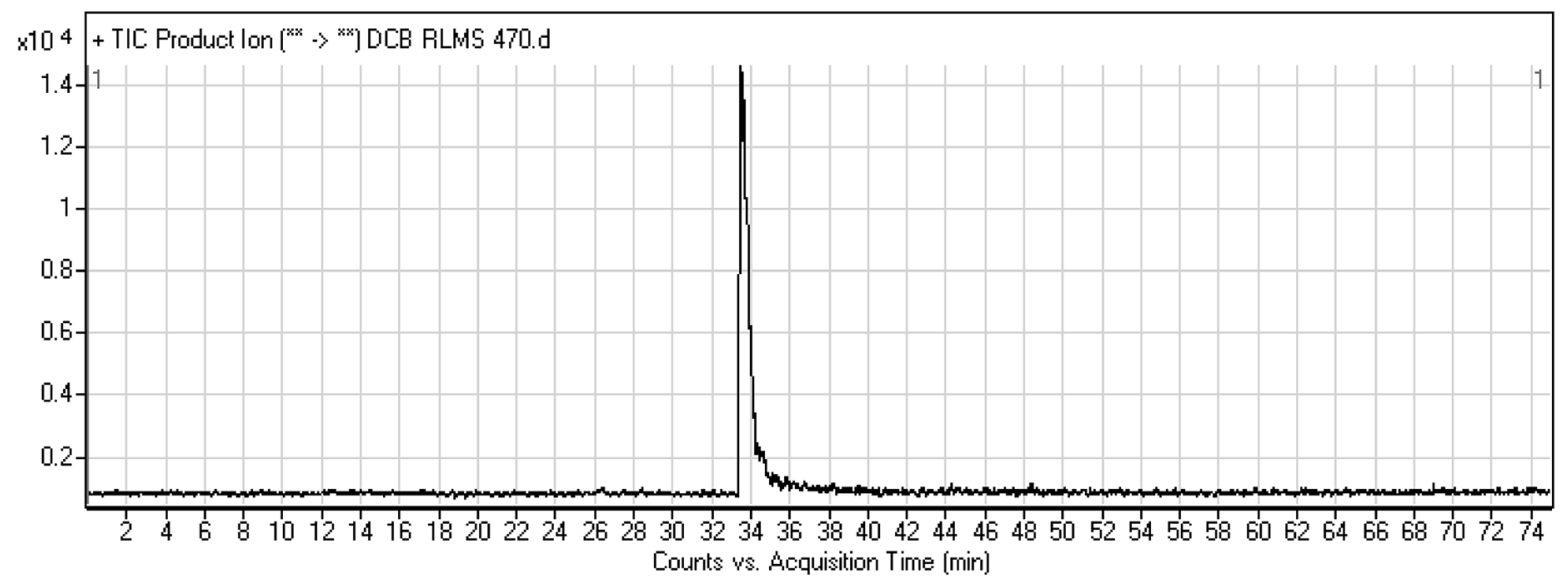

B)

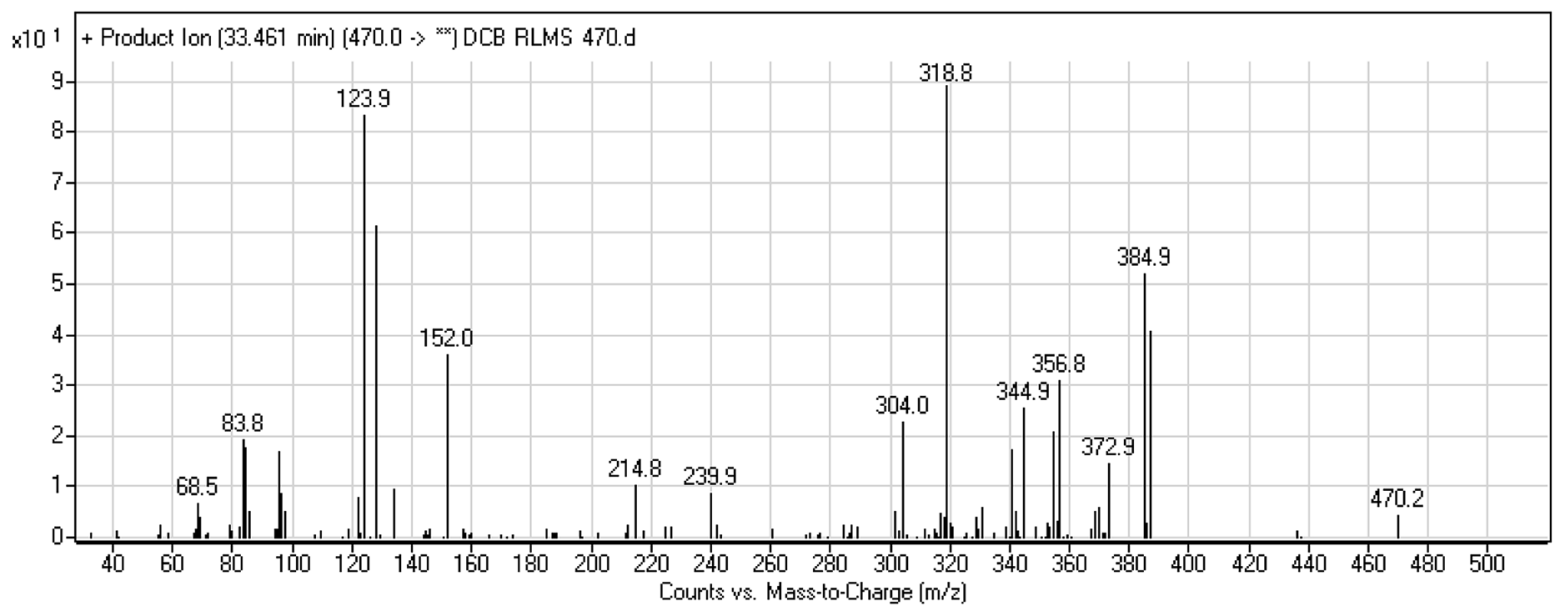

Fig. $1 \mathrm{PI}$ chromatogram of ion at $\mathrm{m} / \mathrm{z} 470$ showing DCB peak at $33.5 \mathrm{~min}$ (A), Pls of DCB (B). 


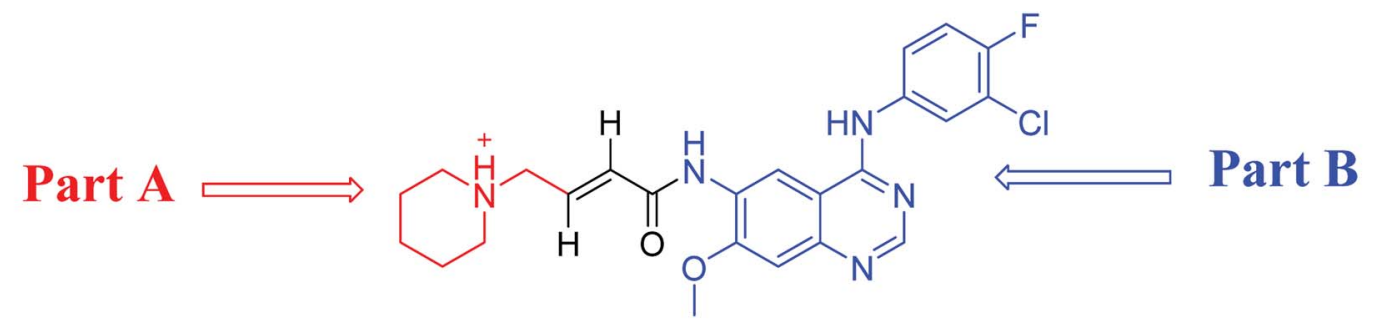

\section{Dacomitinib}

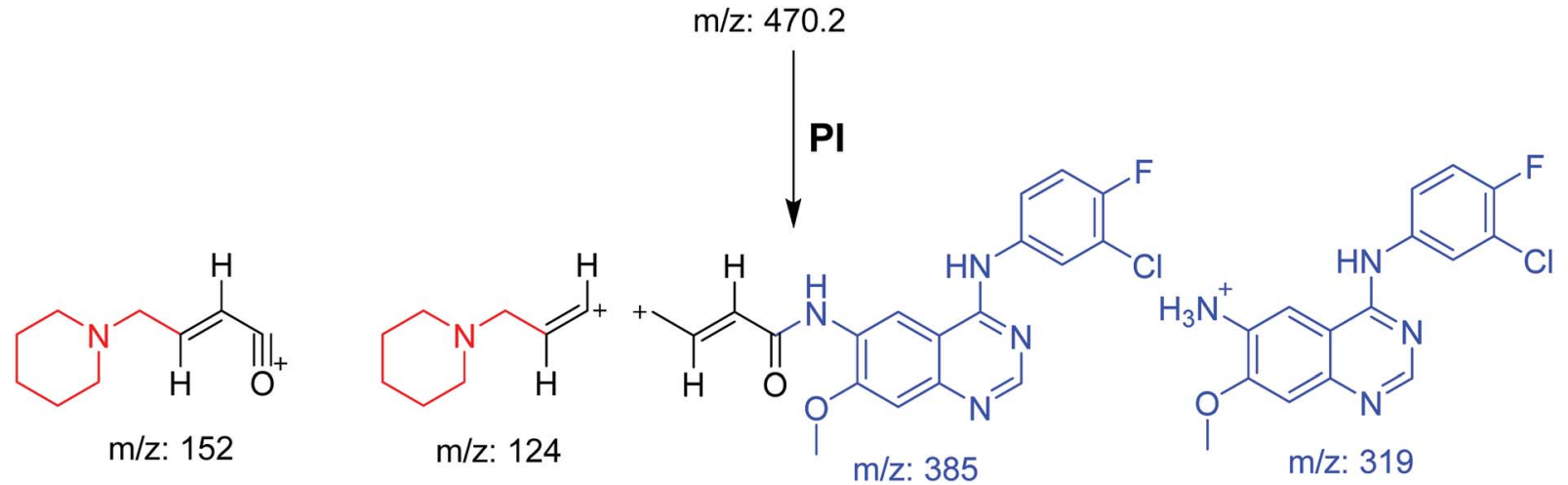

Scheme 1 Pls of DCB.

studies. Reactive metabolites cannot be determined in vivo because as soon as they are formed, they will bind to endogenous materials as DNA or proteins that cannot be detected by mass spectrometry. The basic outcome of this work is identification and characterization of two possible reactive metabolites: one aldehyde and one iminium ion with description of structure details. Bioactivation pathways were also proposed. Four in vitro phase I dacomitinib metabolites were also identified. The presence of such reactive intermediates in DCB metabolism may be the reason of its side effects as they are regarded the first step in drug-induced organ toxicities. ${ }^{32}$

\section{Chemicals and methods}

\subsection{Chemicals}

HPLC grade solvents were utilized throughout the entire study. Dacomitinib reference standard was acquired from Med Chem. Express (Princeton, NJ, USA). Acetonitrile (ACN), ammonium formate $\left(\mathrm{NH}_{4} \mathrm{COOH}\right)$, potassium cyanide $(\mathrm{KCN})$, methoxyl amine $\left(\mathrm{MeONH}_{2}\right)$ and formic acid $(\mathrm{HCOOH})$ were procured from Sigma-Aldrich (USA). Water (ultrapure) was taken from inhouse Milli-Q plus purification system (Millipore, Midford, MA USA). Rat liver microsomes (RLMs) were acquired in-house using Sprague Dawley rats. ${ }^{33-36}$ The used rats were attained from the experimental animal care center at college of Pharmacy, King Saud University (KSA). The University's Ethics Review Committee approved the animal experimental design.

\subsection{Chromatography}

The optimized LC-MS/MS chromatographic parameters for the separation and elucidation of incubation mixture extract components are listed in Table 1.

\subsection{RLMs incubations}

Metabolic reactions were done by incubation $30 \mu \mathrm{M}$ of DCB with $1.0 \mathrm{mg} \mathrm{mL}{ }^{-1} \mathrm{RLMs}$ in addition to $50 \mathrm{mM} \mathrm{Na} / \mathrm{K}$ phosphate buffer (pH 7.4) that contains $3.3 \mathrm{mM} \mathrm{MgCl}$. Incubation was done at $37^{\circ} \mathrm{C}$ for $2 \mathrm{~h}$ in a temperature-controlled rocking water bath. The addition of 1.0 mM NADPH started the metabolic reactions

Table 2 In vitro phase I and reactive metabolites of DCB

\begin{tabular}{lllll}
\hline & MS scan & Most abundant fragment ions & Rt. (min) & Metabolic reaction \\
\hline DCB & 470 & $385,319,152,124$ & 33.5 & Parent drug \\
DCB484 & 484 & $385,319,166,144$ & 39.5 & $\alpha$ Oxidation at piperidine ring \\
DCB472 & 472 & $387,321,152,124$ & 32.2 & Reduction at quinazoline ring \\
DCB486a & 486 & $387,166,138$ & 39.2 & $\alpha$ Oxidation at piperidine ring and reduction at quinazoline ring \\
DCB486b & 486 & $385,319,168$ & 30.4 & Hydroxylation at piperidine ring \\
DCB495 & 495 & $385,319,122$ & 52.5 & Cyano adduct \\
DCB362 & 362 & 332,305 & 38.7 & Methoxyl amine conjugate (oxime)
\end{tabular}


A)

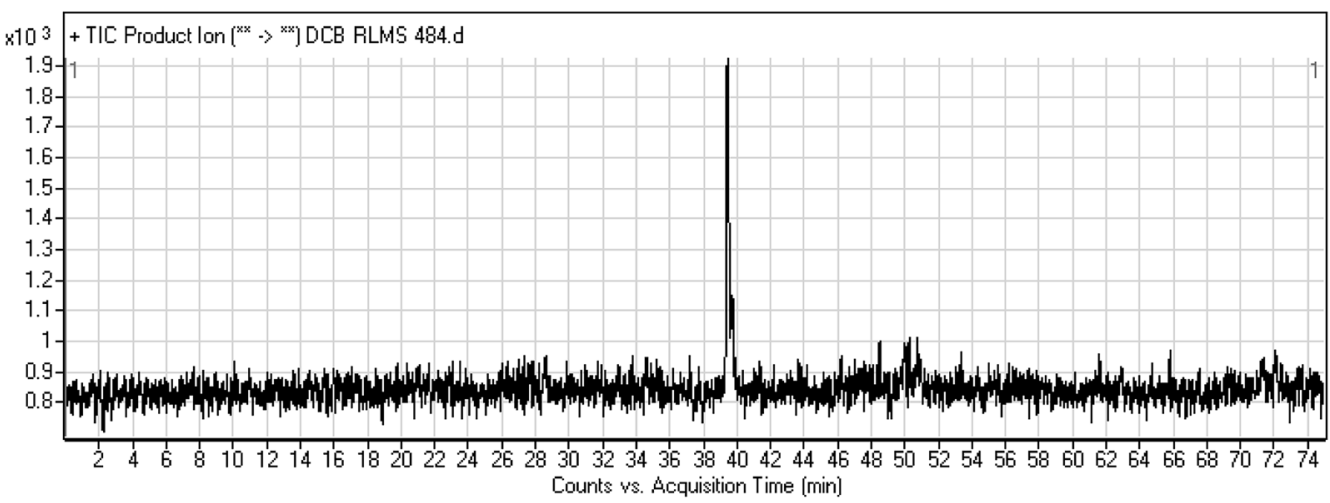

B)

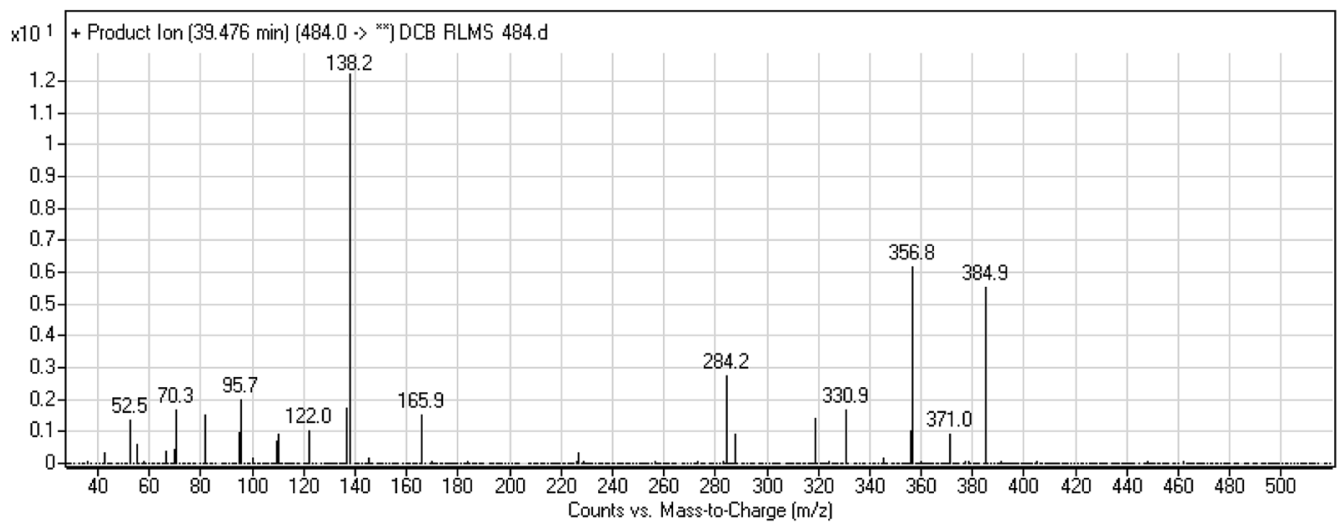

Fig. 2 PI chromatogram of ion at $\mathrm{m} / \mathrm{z} 484$ showing DCB484 peak at $39.5 \mathrm{~min}$ (A), Pls of DCB484 (B).

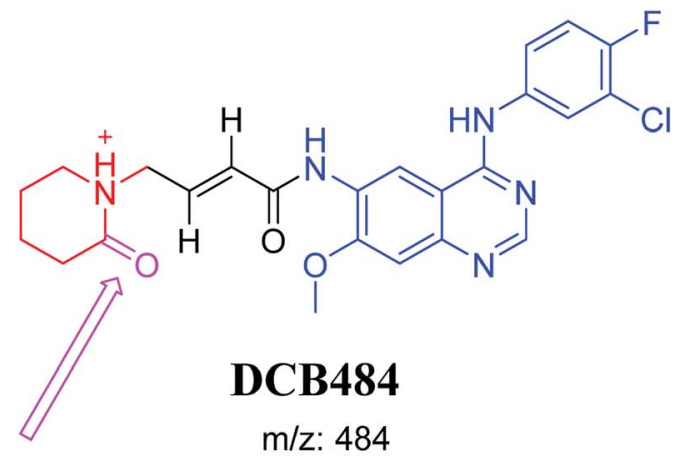

Oxidation as metabolic change<smiles>O=CC=CCN1CCCCC1=O</smiles>

$\mathrm{m} / \mathrm{z}: 166$<smiles>C=CCN1CCCCC1=O</smiles>
$\mathrm{m} / \mathrm{z}: 138$ $\mathrm{m} / \mathrm{z}: 484$

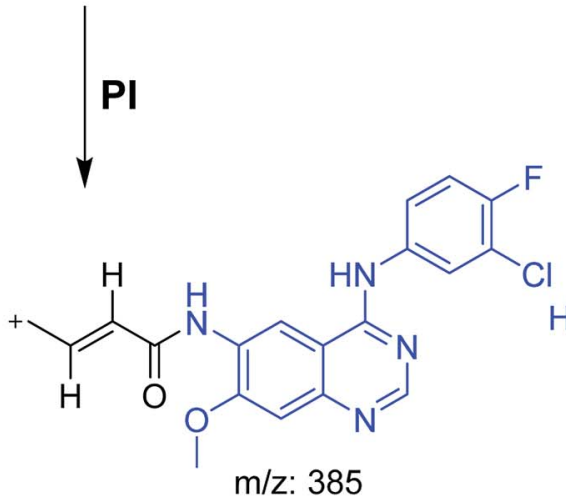<smiles>COc1cc2ncnc(Nc3ccc(F)c(Cl)c3)c2cc1[NH3+]</smiles>

$\mathrm{m} / \mathrm{z}: 319$

Scheme 2 Pls of DCB484. 
while the addition of $2 \mathrm{~mL}$ ice-cold ACN was utilized to quench those reaction.

\subsection{Extraction and purification method of DCB RLMs incubations}

Protein precipitation method by ACN was performed to extract and purify DCB, its in vitro phase I metabolites and its adduct from RLMs incubation mixtures. Removal of proteins was done by centrifugation of metabolic mixtures at $9000 \mathrm{~g}$ for $15 \mathrm{~min}$ at $4{ }^{\circ} \mathrm{C}$. Supernatants were transferred to clean tubes. Evaporation of the supernatants was done under nitrogen stream. The mobile phase was used to reconstitute the residues and $1 \mathrm{~mL}$ from each was put in HPLC vial. Fifteen $\mu \mathrm{L}$ were injected into LC system. ${ }^{36-38}$

\subsection{Characterization of DCB bioactive intermediates}

The same metabolic incubation of DCB with RLMs was repeated in the presence of $2.5 \mathrm{mM}$ methoxyl amine and $1.0 \mathrm{mM} \mathrm{KCN}$ to seize the aldehyde intermediates and reactive iminium intermediates, respectively. Each experiment was repeated three times to verify the outcomes. Three controls were prepared to confirm the results. Control 1 (C1) contains all incubation ingredients including DCB and RLMs except NADH and nucleophiles to confirm in vitro phase I metabolites. C2 contains all incubation ingredients including RLMs except $\mathrm{NADH}$ and DCB to confirm the absence of any interference from indigenous materials. C3 contains all incubation ingredients including NADH and DCB and nucleophiles ( $\mathrm{KCN}$ or $\mathrm{MeONH}_{2}$ ) except RLMs to further proof that the reactive metabolites formation occurred only through metabolic reaction.

\subsection{Identification of DCB reactive metabolites}

Full mass scan and extracted ion chromatograms were utilized to annotate metabolites in the incubation mixtures, while product ion (PI) was employed to identify DCB in vitro metabolites, adducts and reactive intermediates formed in DCB metabolism. Locating metabolites in metabolic mixture extract chromatogram was performed by EIC of $\mathrm{m} / \mathrm{z}$ of the proposed DCB metabolites.

\section{A)}

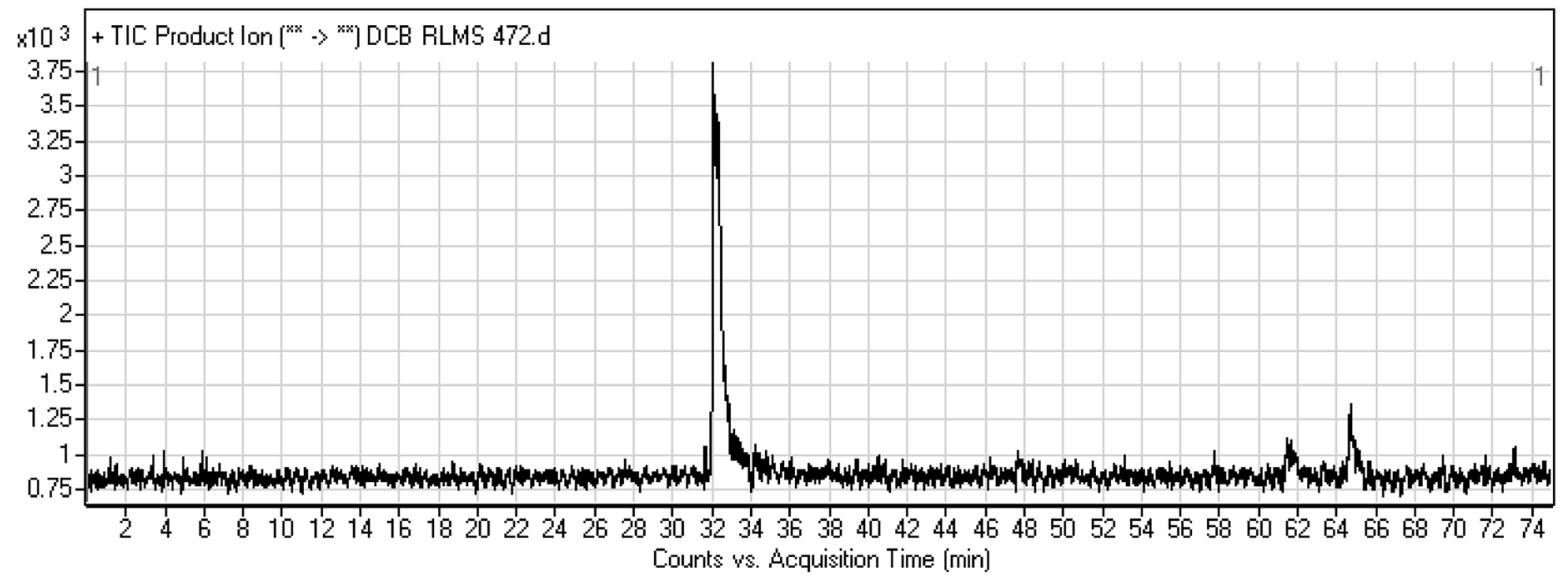

B)

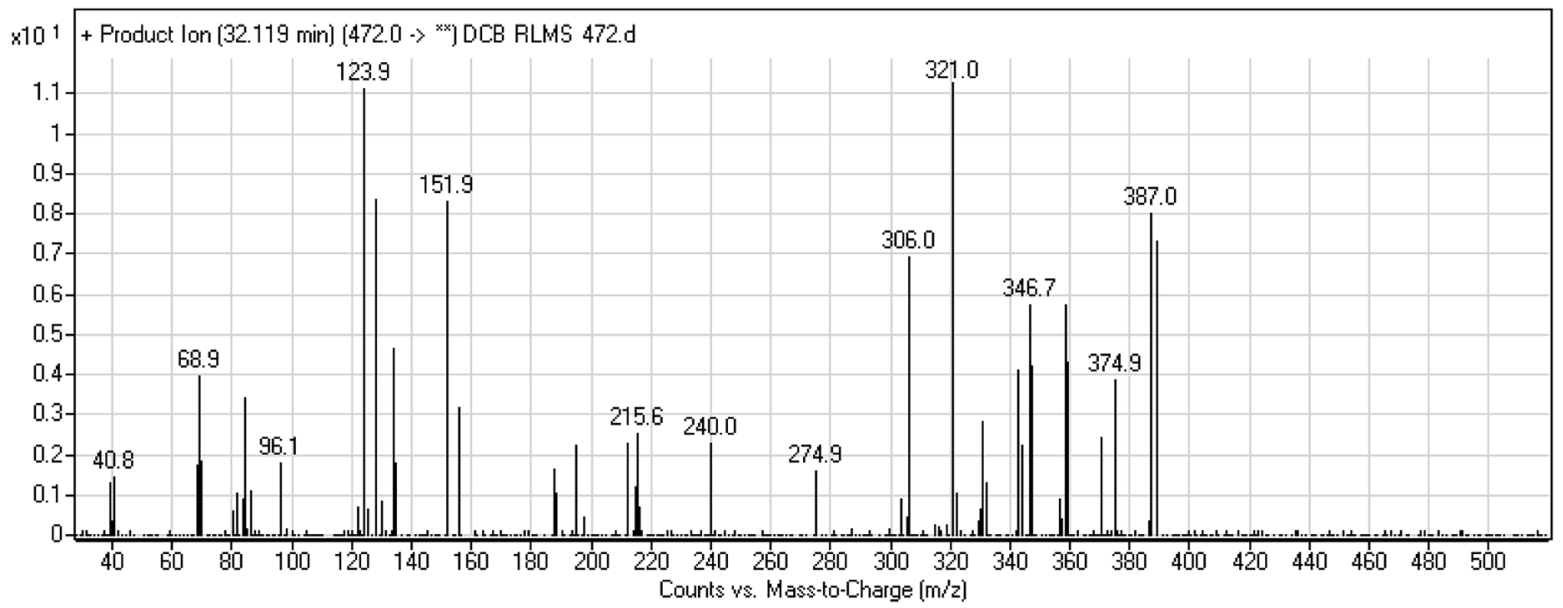

Fig. 3 PI chromatogram of ion at $m / z 472$ showing DCB472 peak at $32.1 \mathrm{~min}$ (A), Pls of DCB472 (B). 


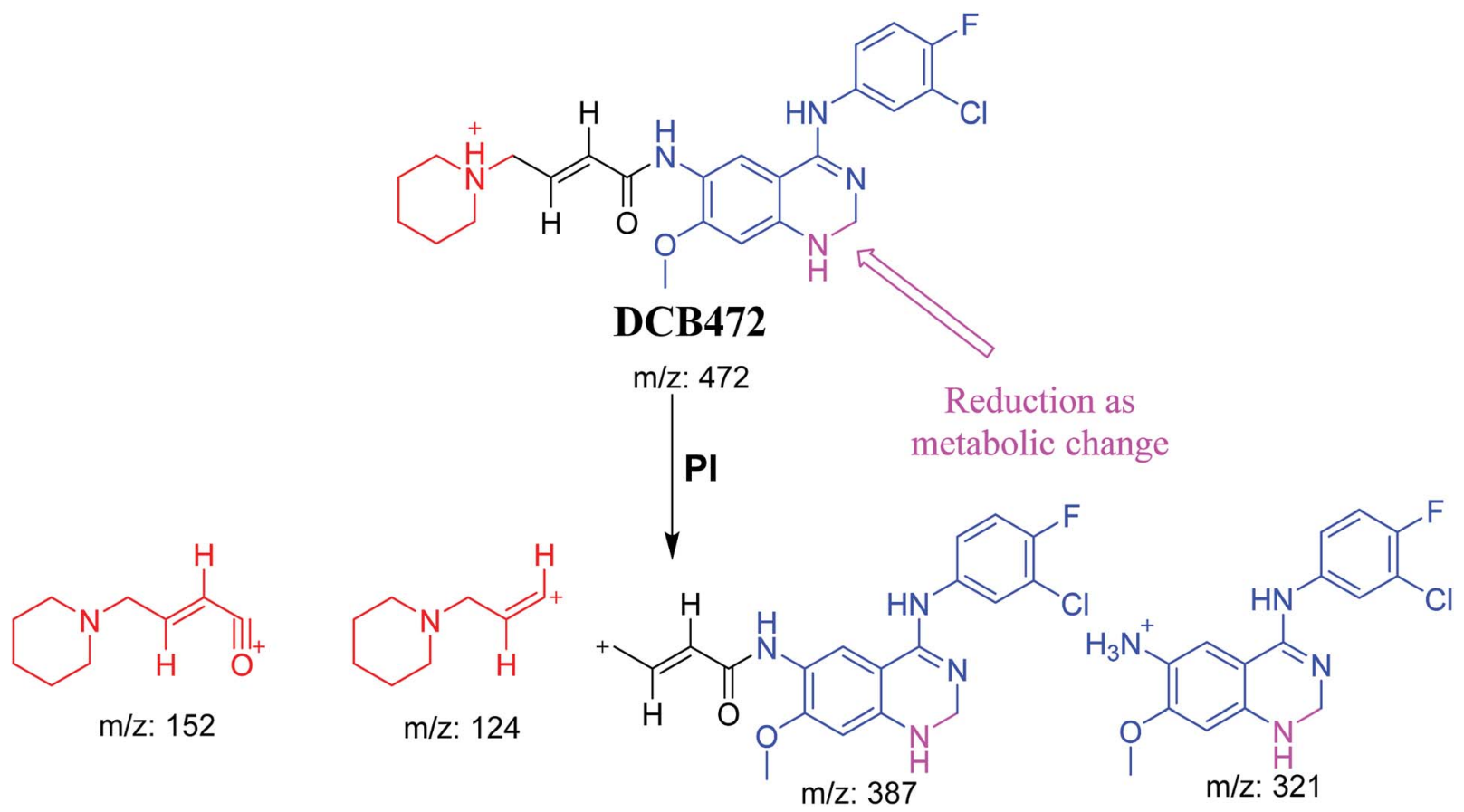

Scheme 3 PIs of DCB472.

A)

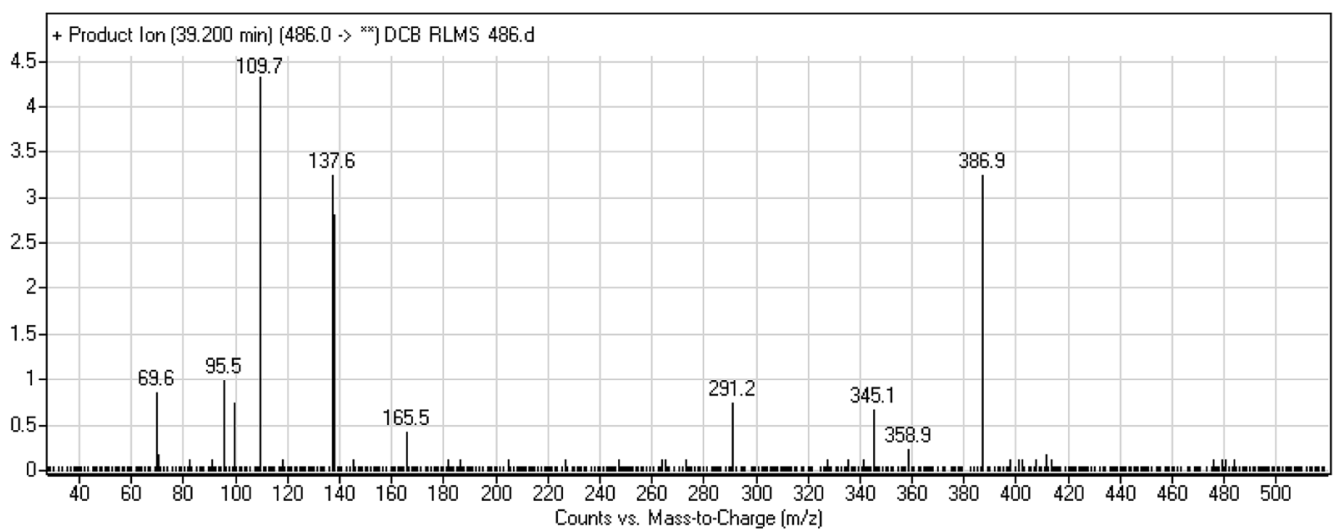

B)

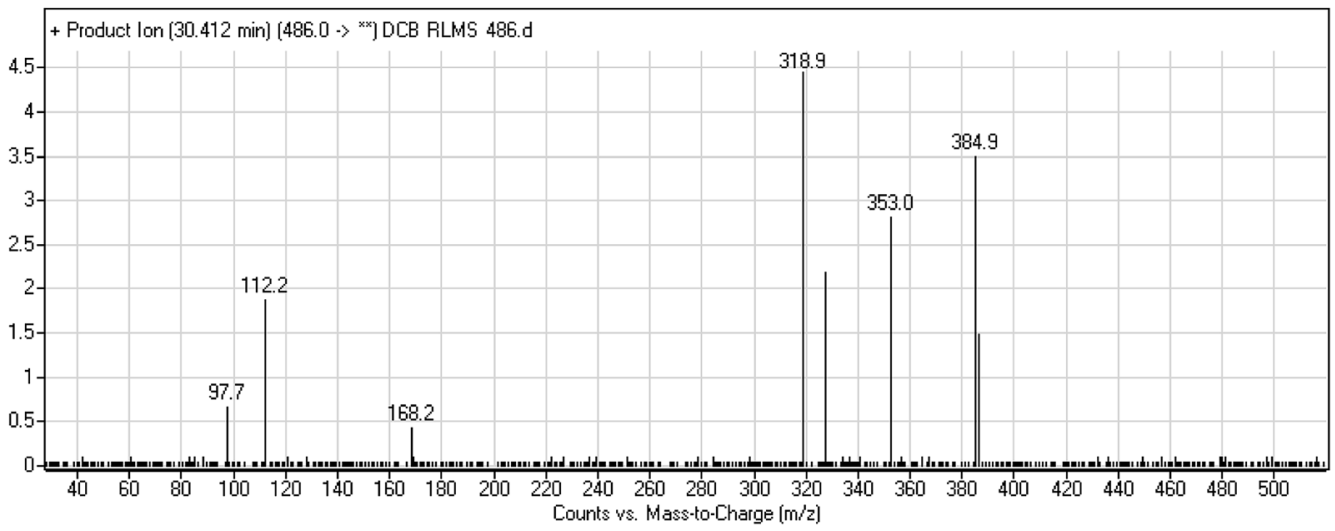

Fig. 4 Pls of DCB486a (A), Pls of DCB486b (B). 




Scheme 4 Pls of DCB486a.

\section{Results and discussion}

\subsection{PI study of DCB}

DCB chromatographic peak appears at 33.5 min in PI chromatogram (Fig. 1A). Collision induced dissociation (CID) of molecular ion at $m / z 470$ generates four characteristic fragment ions at $\mathrm{m} / \mathrm{z} 385, \mathrm{~m} / \mathrm{z} 319, \mathrm{~m} / \mathrm{z} 152$ and $\mathrm{m} / \mathrm{z} 124$ (Fig. 1B). Fragment ions at $\mathrm{m} / \mathrm{z} 152$ and $\mathrm{m} / \mathrm{z} 124$ were used as indicator for any metabolic change in part A of DCB chemical structure while fragment ions at $m / z 385$ and $m / z 319$ were used as indicator for any metabolic change in part B of DCB chemical structure (Scheme 1).<smiles>COc1cc2ncnc(Nc3ccc(F)c(Cl)c3)c2cc1NC(=O)/C=C/CN1CCCCC1O</smiles>

Hydroxylation as metabolic change<smiles></smiles>
$\mathrm{m} / \mathrm{z}: 168$<smiles>C=C(Cl)/C=C(\C)Nc1ncnc2cc(OC)c(NC(=O)C=CC)cc12</smiles>
$\mathrm{m} / \mathrm{z}: 385$<smiles>COc1cc2ncnc(Nc3ccc(F)c(Cl)c3)c2cc1[NH3+]</smiles>

Scheme 5 PIs of DCB486b. 


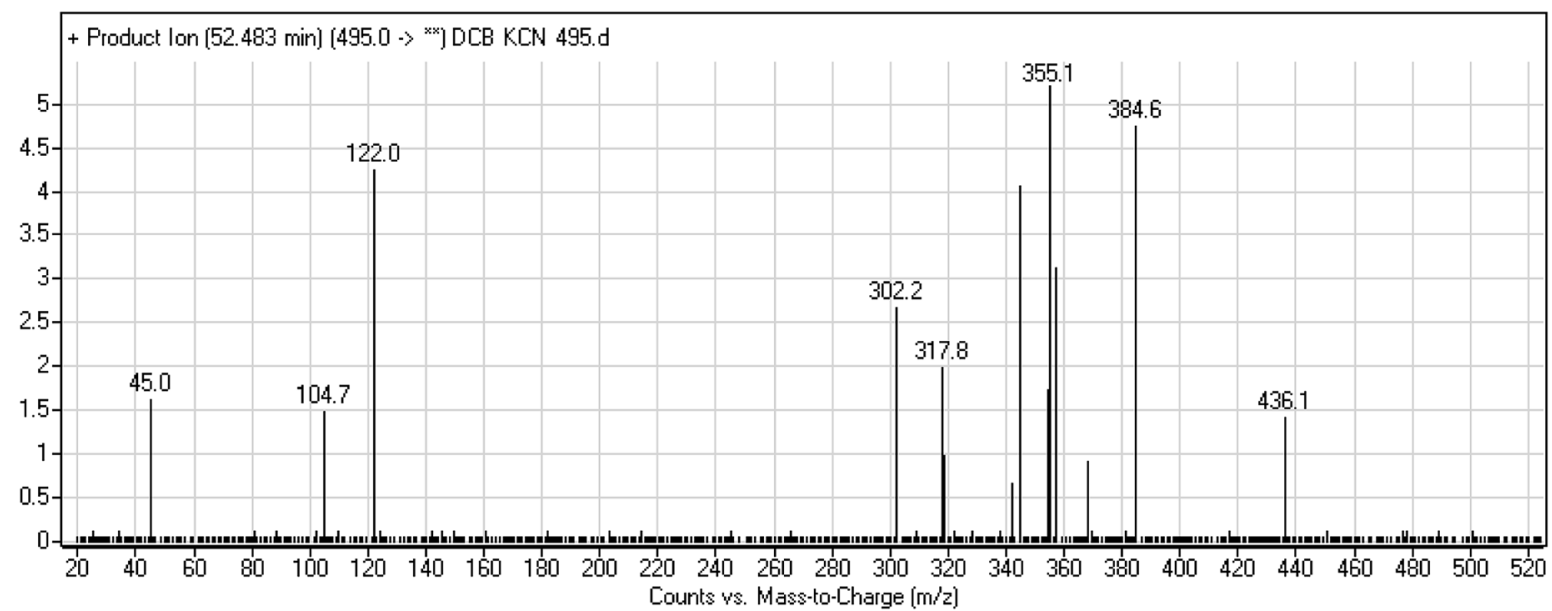

Fig. 5 PI mass spectrum of DCB495.

\subsection{Identification of in vitro DCB metabolites}

After extraction and purification of RLMs incubations, fifteen $\mu \mathrm{L}$ were injected into LC-MS/MS instrument. Major metabolic phase I pathway for DCB was piperidine ring hydroxylation. One methoxyl amine conjugate and one cyano adduct were characterized after incubation with RLMs with $2.5 \mathrm{mM}$ methoxylamine and $1.0 \mathrm{mM}$ KCN, respectively (Table 2).

3.2.1. DCB484 phase I metabolite. DCB484 chromatographic peak appears at $39.5 \mathrm{~min}$ in PI chromatogram (Fig. 2A). CID of molecular ion at $\mathrm{m} / \mathrm{z} 484$ generates four characteristic fragment ions at $\mathrm{m} / \mathrm{z} 385, \mathrm{~m} / \mathrm{z} 319, \mathrm{~m} / \mathrm{z} 166$ and $m / z 138$ (Fig. 2B). In contrast to DCB fragmentation, fragment ions at $m / z 166$ and $m / z 138$ indicated that metabolic alteration took place in part A of DCB chemical structure while fragment ions at $\mathrm{m} / z 385$ and $\mathrm{m} / \mathrm{z} 319$ indicated that no metabolic change occurred in part B of DCB chemical structure. $\alpha$ Oxidation metabolic reaction was hypothesized to take place in piperidine ring (Scheme 2).

3.2.2. DCB472 phase I metabolite. DCB472 chromatographic peak appears at $32.1 \mathrm{~min}$ in PI chromatogram (Fig. 3A). CID of molecular ion at $m / z 472$ generates four characteristic fragment ions at $m / z 387, m / z 321, m / z 152$ and $m / z 124$ (Fig. 3B). In contrast to DCB fragmentation, fragment ions at $m / z 152$ and $m / z 124$ indicated that no metabolic modification took place in part A of DCB chemical structure while fragment ions at $\mathrm{m} / z 387$ and $m / z 321$ indicated that there was a metabolic change in part $B$ of the DCB chemical structure. Reduction metabolic reaction was suggested to take place in quinazoline ring (Scheme 3).

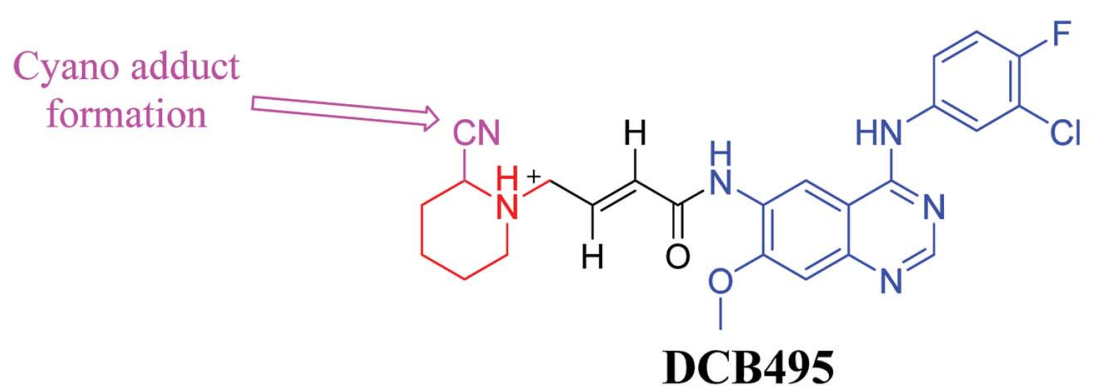

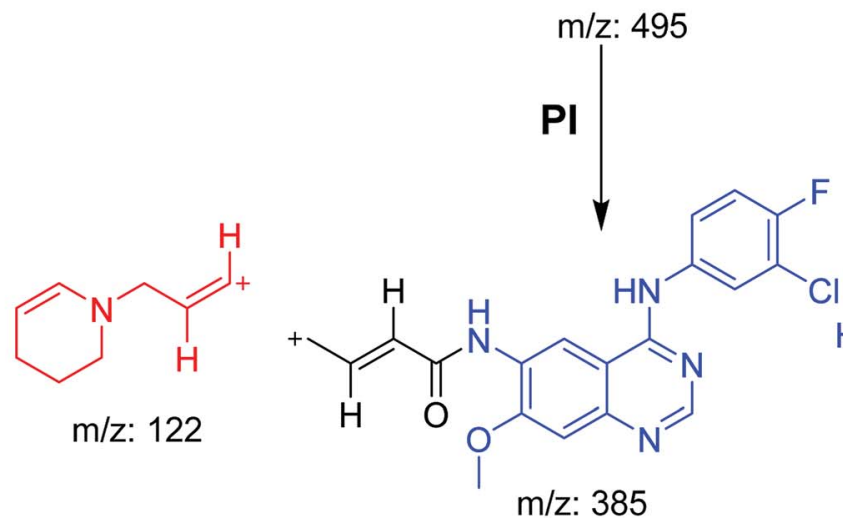<smiles>COc1cc2ncnc(Nc3ccc(F)c(Cl)c3)c2cc1[NH3+]</smiles>

$\mathrm{m} / \mathrm{z}: 319$ 


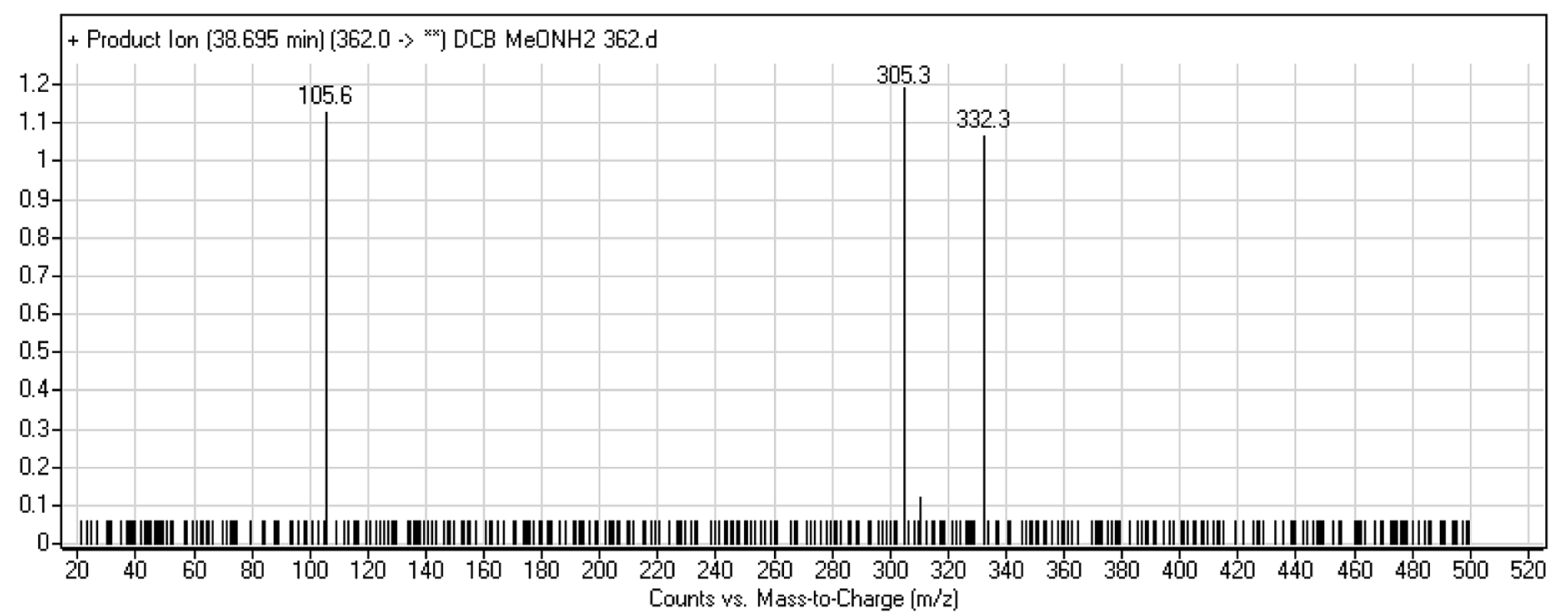

Fig. 6 PI mass spectrum of DCB362.

3.2.3. DCB486 phase I metabolites (a to b). DCB486 chromatographic peaks appear at $39.2 \mathrm{~min}$ and $30.4 \mathrm{~min}$ in the PI chromatogram. For DCB486a, CID of molecular ion at $\mathrm{m} / \mathrm{z} 486$ generated three characteristic ions at $\mathrm{m} / \mathrm{z} 387, \mathrm{~m} / \mathrm{z} 166$ and $\mathrm{m} / \mathrm{z} 138$ (Fig. 4A). In contrast to DCB fragmentation, fragment ions at $\mathrm{m} / \mathrm{z}$ 166 and $m / z 138$ indicated that $\alpha$ oxidation metabolic alteration took place in part A of DCB chemical structure while fragment ions at $m / z 387$ indicated that another reduction metabolic change occurred in part B of DCB chemical structure. $\alpha$-Oxidation metabolic reaction was assumed to occur in piperidine ring in addition to a reduction reaction in quinazoline ring (Scheme 4).

In case of DCB486b, (CID) of molecular ion at $\mathrm{m} / \mathrm{z} 486$ generates three characteristic fragment ions at $\mathrm{m} / \mathrm{z} 385, \mathrm{~m} / \mathrm{z} 319$ and $m / z 168$ (Fig. 4B). In comparison to DCB fragmentation, fragment ions at $\mathrm{m} / \mathrm{z} 385$ and $\mathrm{m} / \mathrm{z} 319$ indicated that $\alpha$ oxidation metabolic change occurred in part B of DCB chemical structure while fragment ions at $m / z 168$ indicated that another reduction metabolic change occurred in part A of DCB chemical structure.

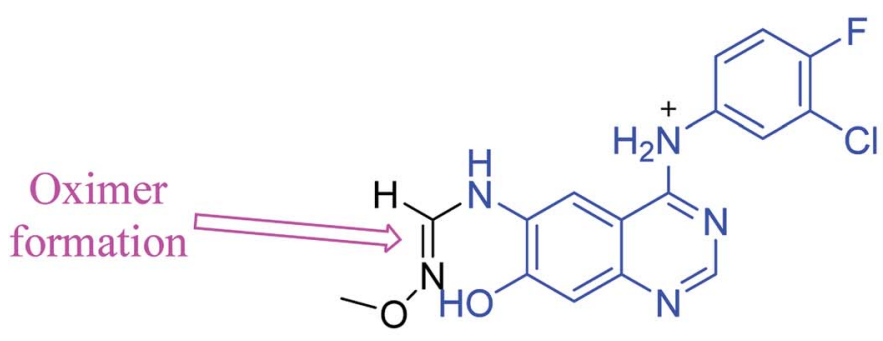

\section{DCB362}<smiles>Nc1cc2c([NH2+]c3ccc(F)c(Cl)c3)ncnc2cc1O</smiles>

$\mathrm{m} / \mathrm{z}: 305$<smiles>N=C(N)Nc1cc2c([NH2+]c3ccc(F)c(Cl)c3)ncnc2cc1O</smiles>

$\mathrm{m} / \mathrm{z}: 332$ 




Scheme 8 Proposed pathways for DCB bioactivation.

Hydroxylation reaction was hypothesized to metabolically occur in piperidine ring of DCB (Scheme 5).

3.2.4. DCB495 cyano adduct. DCB495 chromatographic peak appears at $52.5 \mathrm{~min}$ in PI chromatogram. CID of molecular ion at $\mathrm{m} / \mathrm{z} 495$ generates three characteristic fragment ions at $\mathrm{m} /$ $z 385, \mathrm{~m} / z 319$ and $\mathrm{m} / z 122$ (Fig. 5). In contrast to DCB fragmentation, fragment ions at $\mathrm{m} / z 385$ and $\mathrm{m} / z 319$ indicated that no metabolic effect on part A of the DCB chemical structure while fragment ions at $\mathrm{m} / \mathrm{z} 122$ indicated that a metabolic modification took place in part B of DCB chemical structure that signified a loss of HCN. In bioactivation of similar piperidine containing drugs, ${ }^{39,40}$ piperidine ring carbons was hypothesized to undergo bioactivation followed by attack by cyanide ion as explained in Scheme 6.

3.2.5. DCB362 oxime adduct of avitinib. DCB362 chromatographic peak appears at $38.69 \mathrm{~min}$ in PI chromatogram. CID of the molecular ion at $\mathrm{m} / \mathrm{z} 362$ generates three characteristic fragment ions at $\mathrm{m} / \mathrm{z} 332, \mathrm{~m} / \mathrm{z} 305$ and $\mathrm{m} / \mathrm{z} 106$ (Fig. 6). In comparison to DCB fragmentation, fragment ions at $m / z 332$ and $\mathrm{m} / \mathrm{z} 305$ indicated that no metabolic change occurred in part B of DCB chemical structure contains butenamide group undergoes bioactivation through oxidative dealkylation to form unstable reactive aldehyde that can be stabilized by reaction with methoxylamine forming oxime. The formation of DCB362 oxime indicated 


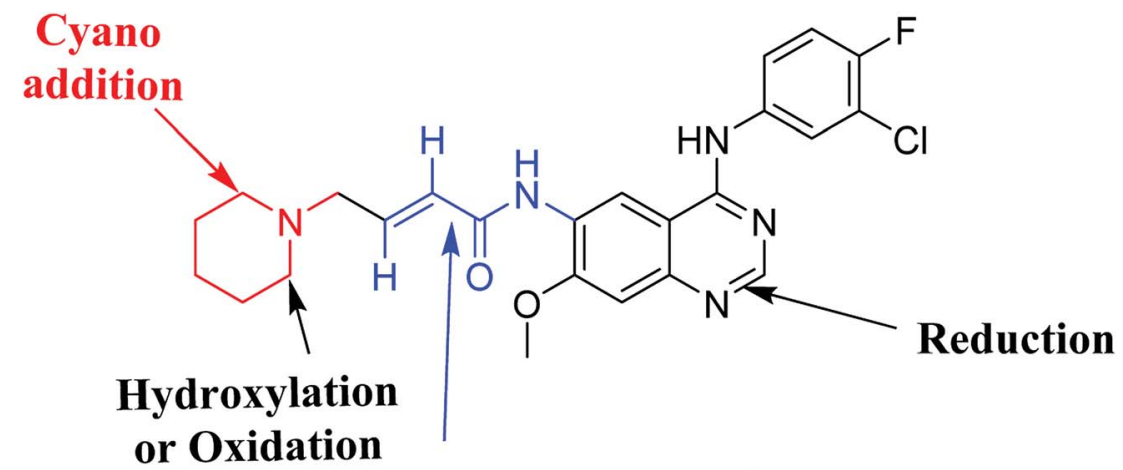

\author{
Oxidative dealkylation \\ Aldhyde formation \\ Oxime formation with methoxyl amine
}

\title{
Dacomitinib
}

Fig. 7 Chemical structure of DCB showing bioactivation pathways including iminium and aldehyde formation.

that aldehyde intermediates were formed in the metabolism of DCB (Scheme 7).

\subsection{Proposed pathways of bioactivation of DCB}

Scheme 8 showed the different pathways for bioactivation of DCB. DCB495 cyanide adduct confirmed iminium intermediate formation in piperidine ring metabolism. Hydroxylation of piperidine ring in DCB followed by dehydration led to generation of unstable and reactive iminium ions intermediates that may be captured by cyanide to form stable adduct which can be detected in LC-MS/MS. The formation pathway of iminium intermediate and bioactivation mechanism of DCB was described earlier with similar drugs encompassing cyclic tertiary amine. ${ }^{36,37}$ The aldehyde (DCB362) was formed by oxidative dealkylation of butenamide group and captured by methoxylamine to form a stable oxime containing compound (Scheme 8).

\section{Conclusions}

Four DCB metabolites were isolated and detected by LC-MS/MS in vitro resulting from phase I metabolic reactions. Two possible reactive metabolites: one aldehyde and one iminium ion were detected and the bio-activation pathways were proposed (Fig. 7). These reactive intermediates in DCB metabolism may be the reason of its side effects as they are considered the primary step in drug-induced organ toxicities. The results obtained in the present study paves the way for the development of new drugs with more safety profile.

\section{Conflicts of interest}

The authors declare no conflict of interest.

\section{Acknowledgements}

"The authors would like to extend their sincere appreciation to the Deanship of Scientific Research at the King Saud University for funding this work through the Research Group Project No. RG-1435-025."

\section{References}

1 R. L. Siegel, K. D. Miller and A. Jemal, Ca-Cancer J. Clin., 2016, 66, 7-30.

2 S. M. Haghgoo, A. Allameh, E. Mortaz, J. Garssen, G. Folkerts, P. J. Barnes and I. M. Adcock, Eur. J. Pharmacol., 2015, 754, 82-91.

3 I. Abubakar, T. Tillmann and A. Banerjee, Lancet, 2015, 385, 117-171.

4 D. S. Ettinger, W. Akerley, G. Bepler, M. G. Blum, A. Chang, R. T. Cheney, L. R. Chirieac, T. A. D'Amico, T. L. Demmy and A. K. P. Ganti, J. Natl. Compr. Cancer Network, 2010, 8, 740-801.

5 J. E. Larsen, T. Cascone, D. E. Gerber, J. V. Heymach and J. D. Minna, Cancer J., 2011, 17, 512.

6 D. B. Costa and S. S. Kobayashi, Transl. Lung Cancer Res., 2015, 4, 809.

7 C. Gridelli, A. Rossi, D. P. Carbone, J. Guarize, N. Karachaliou, T. Mok, F. Petrella, L. Spaggiari and R. Rosell, Nat. Rev. Dis. Primers, 2015, 1, 15009.

8 S. Peters, S. Zimmermann and A. A. Adjei, Cancer Treat. Rev., 2014, 40, 917-926.

9 G. Metro and L. Crinò, Transl. Lung Cancer Res., 2012, 1, 5.

10 M. G. Denis, A. Vallée and S. Théoleyre, Clin. Chim. Acta, 2015, 444, 81-85.

11 S. Jorge, S. Kobayashi and D. Costa, Braz. J. Med. Biol. Res., 2014, 47, 929-939.

12 M. R. Finlay, M. Anderton, S. Ashton, P. Ballard, P. A. Bethel, M. R. Box, R. H. Bradbury, S. J. Brown, S. Butterworth, A. Campbell, C. Chorley, N. Colclough, D. A. Cross, G. S. Currie, M. Grist, L. Hassall, G. B. Hill, D. James, M. James, P. Kemmitt, T. Klinowska, G. Lamont, S. G. Lamont, N. Martin, H. L. McFarland, M. J. Mellor, J. P. Orme, D. Perkins, P. Perkins, G. Richmond, P. Smith, 
R. A. Ward, M. J. Waring, D. Whittaker, S. Wells and G. L. Wrigley, J. Med Chem., 2014, 57, 8249-8267.

13 C.-S. Tan, D. Gilligan and S. Pacey, Lancet Oncol., 2015, 16, e447-e459.

14 B.-C. Liao, C.-C. Lin and J. C.-H. Yang, Curr. Opin. Oncol., 2015, 27, 94-101.

15 P. A. Jänne, J. C.-H. Yang, D.-W. Kim, D. Planchard, Y. Ohe, S. S. Ramalingam, M.-J. Ahn, S.-W. Kim, W.-C. Su and L. Horn, N. Engl. J. Med., 2015, 372, 1689-1699.

16 Y. L. Wu, Y. Cheng, X. Zhou, K. H. Lee, K. Nakagawa, S. Niho, F. Tsuji, R. Linke, R. Rosell, J. Corral, M. R. Migliorino, A. Pluzanski, E. I. Sbar, T. Wang, J. L. White, S. Nadanaciva, R. Sandin and T. S. Mok, Lancet Oncol., 2017, 18, 1454-1466.

17 U.S. Food and Drug Administration (FDA), Vizimpro® (dacomitinib) tablets, 27th September 2018.

18 F. Barrón, Z. L. Zatarain-Barrón, A. F. Cardona and O. Arrieta, J. Thorac. Dis., 2018, 10, 1265.

19 C. Brzezniak, C. A. Carter and G. Giaccone, Expert Opin. Pharmacother., 2013, 14, 247-253.

20 K. Sanderson, Nat. Rev. Drug Discovery, 2013, 12, 649-651.

21 K. L. Reckamp, G. Giaccone, D. R. Camidge, S. M. Gadgeel, F. R. Khuri, J. A. Engelman, M. Koczywas, A. Rajan, A. K. Campbell and D. Gernhardt, Cancer, 2014, 120, 11451154.

22 S. R. Knowles, J. Uetrecht and N. H. Shear, Lancet, 2000, 356, 1587-1591.

23 C. Ju and J. Uetrecht, Curr. Drug Metab., 2002, 3, 367-377.

24 S. Ma and M. Zhu, Chem.-Biol. Interact., 2009, 179, 25-37.

25 A. F. Stepan, D. P. Walker, J. Bauman, D. A. Price, T. A. Baillie, A. S. Kalgutkar and M. D. Aleo, Chem. Res. Toxicol., 2011, 24, 1345-1410.

26 L. P. Masic, Curr. Drug Metab., 2011, 12, 35-50.
27 Z. Zhang, Q. Chen, Y. Li, G. A. Doss, B. J. Dean, J. S. Ngui, M. Silva Elipe, S. Kim, J. Y. Wu, F. Dininno, M. L. Hammond, R. A. Stearns, D. C. Evans, T. A. Baillie and W. Tang, Chem. Res. Toxicol., 2005, 18, 675-685.

28 B. K. Park, A. Boobis, S. Clarke, C. E. Goldring, D. Jones, J. G. Kenna, C. Lambert, H. G. Laverty, D. J. Naisbitt and S. Nelson, Nat. Rev. Drug Discovery, 2011, 10, 292-306.

29 S. Ma and R. Subramanian, J. Mass Spectrom., 2006, 41, 1121-1139.

30 A. Tolonen, M. Turpeinen and O. Pelkonen, Drug discovery today, 2009, 14, 120-133.

31 C. L. Bello, E. Smith, A. Ruiz-Garcia, G. Ni, C. Alvey and C.-M. Loi, Cancer Chemother. Pharmacol., 2013, 72, 379-385.

32 X. Xu, L. Mao, W. Xu, W. Tang, X. Zhang, B. Xi, R. Xu, X. Fang, J. Liu and C. Fang, Molecular cancer therapeutics, 2016.

33 R. von Jagow, H. Kampffmeyer and M. Kiese, NaunynSchmiedebergs Arch. Exp. Pathol. Pharmakol., 1965, 251, 7387.

34 A. A. Kadi, M. Attwa and H. W. Darwish, RSC Adv., 2018, 8, 1182-1190.

35 S. M. Amer, A. A. Kadi, H. W. Darwish and M. W. Attwa, RSC Adv., 2017, 7.

36 A. A. Kadi, H. W. Darwish, M. W. Attwa and S. M. Amer, $R S C$ Adv., 2016, 6, 72575-72585.

37 S. M. Amer, A. A. Kadi, H. W. Darwish and M. W. Attwa, RSC Adv., 2017, 7, 4479-4491.

38 A. A. Kadi, A. S. Abdelhameed, H. W. Darwish, M. W. Attwa and N. S. Al-Shakliah, Biomed. Chromatogr., 2016, 30, 1248-1255.

39 L. P. Masic, Curr. Drug Metab., 2011, 12, 35-50.

40 N. Castagnoli Jr, J. M. Rimoldi, J. Bloomquist and K. P. Castagnoli, Chem. Res. Toxicol., 1997, 10, 924-940. 